CHAPTER 6:

\title{
Participation and Enrollment
}

This chapter of the report presents information about children's participation in ECE services in the eight study countries. These data inform readers about the levels of child participation in ECE for subgroups of the population and at different ages, prioritizing or targeting strategies for setting enrollment, how settings reflect diversity and cultural difference, the coverage and availability of provision, the cost to parents for participation and the use of early intervention programs targeted at subgroups of the population. Within and between country similarities and variations in enrollment and participation are highlighted.

As mentioned previously (page 22), the benefits to children of attending ECE settings have been clearly demonstrated, including those that relate to addressing social inequalities (Corak et al., 2012; Karoly et al., 2005; Pascal, \& Bertram, 2012; Sylva et al., 2004, 2008). This evidence underlines the importance of children from less advantaged backgrounds participating in high quality ECE services. Many countries are developing policies to increase and widen the participation of children in ECE services, particularly in the PPE phase. Yet, despite these positive signs, there remains evidence (Corak et al., 2012; OECD, 2012b; Pascal, \& Bertram, 2012) that achieving full participation for certain populations is challenging, for example for children with special needs or disability, children with certain health conditions, children from lowincome households and children from some ethnic minorities. There is evidence that the barriers to participation, (such as costs, cultural insensitivity, limited physical access, and lack of appropriately trained staff) for these groups contribute substantially to the inequalities in educational outcomes. Many young children do not have the benefit of high quality, enriching early education experiences, which, through early intervention, can do much to counter disadvantage, disability, developmental delay and lack of social mobility in young children (Corak et al., 2012; Karoly et al., 2005). It has also been suggested that participation in ECE can help children to be better prepared for school, thereby improving their ability to succeed (Hart, \& Risely, 1995; Heckman, 2000; Pascal, \& Bertram, 2012).

Evidence (OECD 2012b) indicates that, in those countries where publicly-funded free ECE programs exist, they enroll high numbers of the eligible age group across socioeconomic levels. Where early education is not a free and universal entitlement, market pricing generally determines which parents can afford to send their children and where they can send them. It is also often the case that families of children with special needs find it more difficult to access private and voluntary sector provision due to the costs involved in supporting these children (OECD, 2006). There is increasing international evidence (Corak et al., 2012) that, in many countries, children from lowincome families continue to be less likely to attend high quality early education and care programs, even though they benefit more than their more advantaged peers. Estimates indicate that if all children from low-income families were to be enrolled in high quality early education programs, such reforms could close the gap in achievement by as much as $20-50 \%$, revealing what a powerful driver early education can be in countering socioeconomic disadvantage (Corak et al., 2012; Pascal, \& Bertram, 2012).

Given this wider evidential context, the ECES explored the enrollment levels of children in ECE from different populations, how enrollment levels are enhanced, and systemic factors that might affect this participation in the eight study countries. 


\section{Levels of Participation in ECE Programs for Children from Subgroups of the Overall Population}

To enhance participation in ECE programs, countries can provide legal entitlements to enable all children to access affordable, high-quality ECE. In particular, many countries have started to offer free universal ECE services to certain age groups, usually one or two years before the start of compulsory schooling; this does seem to result in high levels of participation (EIU, 2012; OECD, 2012b). Further research (OECD, 2012b) suggests that even with this entitlement children from low-income families, ethnic minorities (including immigrants), and those with disabilities or special needs, continue to have lower levels of participation than other groups. The evidence also reveals that the enrollment of children with these characteristics in ECE services is often dependent on the policy decisions made in each country. For example, those countries in the study providing subsidized, publically-funded ECE have a larger proportion of the eligible age cohort enrolled. ECE services, especially those that are not publically funded, often have lower enrollment of children coming from these subgroup populations (EIU, 2012; OECD, 2012b; Pascal, \& Bertram, 2012). This has significant implications for the educational outcomes of children with these characteristics.

Building on the evidence presented in Chapter 5 (Table 9) on total enrollment levels in ECE services at different ages, the ECES policy data explored the levels of enrollment in ECE services for subgroups of children in the overall population at different ages in the eight study countries. In particular, the study collected information about participation levels of children from low-income families, children with special needs or disability, children from minority ethnic groups and children whose home language is other than the national language (Table 12).

Data on enrollment rates in ECE broken down for children with certain characteristics is often not collected or is less easily available (Table 12). This is a significant data gap for policy development purposes and one which should be addressed if stated country goals for ECE are to be achieved. The Czech Republic, Italy, Poland and the Russian Federation all reported that data was not collected in this way or that this data was hard to access. Four countries were able to supply data: Chile (data on children from lowincome families only), Denmark, Estonia and the United States.

\section{Children from Low-Income Families}

The enrollment data on children from low-income families reveal that the proportion of children falling into this group varies significantly across the study countries, from $75 \%$ in Chile, 24\% in the United States, 15\% in Estonia, to 6\% in Denmark. In Estonia and Denmark, where the proportion of these children in the total population is relatively small, and there is publically-funded universal ECE, enrollment levels of these children are high: in Estonia there is 100\% at both ECED and PPE levels, and, in Denmark, 95\% enrollment for ECED and $97 \%$ for PPE. In Chile, where approximately $75 \%$ of the population is defined as low income, and there is a mix of publicly-funded and private ECE, the enrollment in ECE for ECED-aged children is 12\% and PPE aged children is $49 \%$. Within the United States, approximately $24 \%$ of PPE and ECED aged children live in poverty, with 13\% of low-income ECED aged children enrolled in ECE and 59\% of low-income PPE aged children enrolled in ECE. It is also interesting to note that the evidence presented in the table indicates that in Estonia and Denmark the enrollment level of children from low-income families exceeds the enrollment level of children in 
Table 12: Child characteristics and enrollment levels of children aged from 0-3 years (ECED) and children aged from 3 years to the start of primary schooling (PPE)

\begin{tabular}{|c|c|c|c|c|c|c|c|c|c|c|}
\hline & & \multicolumn{9}{|c|}{ Enrollment of children in ECE services } \\
\hline Country & Level & 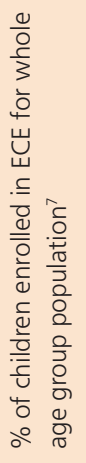 & 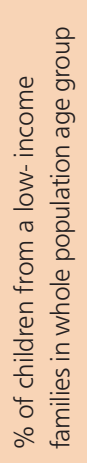 & 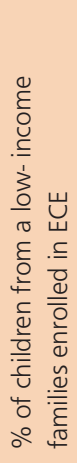 & 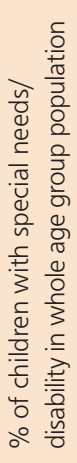 & 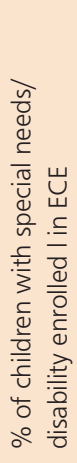 & 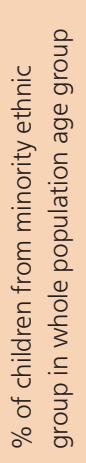 & 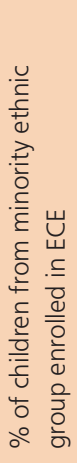 & 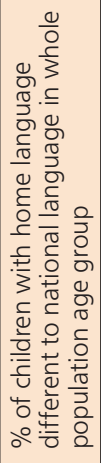 & 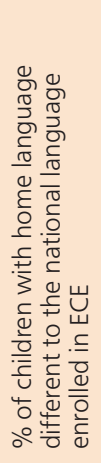 \\
\hline \multirow[t]{2}{*}{ Chile $^{a}$} & ECED & 19 & 75 & 12 & - & - & - & - & - & - \\
\hline & PPE & 67 & 75 & 49 & - & - & - & - & - & - \\
\hline \multirow[t]{2}{*}{ Denmark $^{b}$} & ECED & 66 & 6 & 95 & 5 & 91 & 1 & - & - & - \\
\hline & PPE & 94 & 6 & 97 & 5 & 97 & 1 & 97 & - & - \\
\hline \multirow[t]{2}{*}{ Estonia } & ECED & 24 & 15 & 100 & 11 & 100 & 17 & 100 & 17 & 100 \\
\hline & PPE & 90 & 15 & 100 & 11 & 100 & 17 & 100 & 17 & 100 \\
\hline \multirow[t]{2}{*}{ United States ${ }^{c, d}$} & ECED & 43 & 24 & 13 & 1 & 23 & 49 & 21 & 12 & 13 \\
\hline & PPE e & 61 & 24 & 59 & 5 & 65 & 51 & 61 & 9 & 52 \\
\hline
\end{tabular}

Key:

- No data available.

Explanatory notes:

The Czech Republic, Italy, Poland and the Russian Federation were unable to submit data. NRCs in the Czech Republic, Italy and the Russian Federation pointed out that, as they have universal access to free services (for Italy, only in PPE), they do not collect data for specific child populations, but only on the total number of children enrolled in each age group. No data are available for Italian ECED on the characteristics of users. It was reported that accessing this data was difficult in Poland.

\section{Country specific notes:}

a Chile reported that data are not collected for children with special needs/disability, children from minority ethnic groups and children whose home language is different than the national language.

b Denmark reported that there is universal entitlement to ECED and PPE.

c The United States used the following definitions:

- Low-income family: defined as a household in which household income in the 12 months prior to the survey date is at or below the poverty income threshold set by the US Census Bureau for a household of that size.

- Children with special needs/disability: children whose parents reported that a health or education professional determined the child had a condition and whose parents reported that the condition interferes with the child's ability to learn

- Minority ethnic group: These are children who are not reported as white or children reported as being in multiple racial/ethnic groups.

- Home language is different than the national language: Although the United States does not have an official national language, this characteristic was defined as children who mainly speak a language other than English at home. Children who speak both English and another language equally at home are not included. If a child does not yet speak, home language is determined by the parents' home language.

d In the United States, the \% figure for children with certain characteristics enrolled in ECE within the age group was calculated by dividing the number of children with these characteristics who are enrolled in ECE by the number of children with these characteristics in the age group: (number of children with these characteristics AND in ECE) / (number of children with these characteristics).

e For the United States, PPE includes enrollment in center-based ECE, licensed home-based ECE, and kindergarten. 
the total population. In Chile and the United States, the enrollment figure for children from low-income households is significantly lower than the enrollment level in the total population.

\section{Children with Special Needs or Disability}

The enrollment data on children with special needs or disability reveal that the proportion of children falling into this group is relatively low in all three study countries that submitted data: 5\% in Denmark, $11 \%$ in Estonia and 1-5\% in the United States. In Denmark and Estonia, where there is publicly-funded universal ECE, the enrollment level of these children is very high: in Denmark, 91\% for ECED and 97\% for PPE and, in Estonia, 100\% for both. In the United States, where there is targeted funded entitlement, the enrollment level is significantly lower, $23 \%$ of these children are enrolled in ECED services, $31 \%$ in PPE services up to the age of kindergarten, and 35\% in kindergarten. These data reveal the very different level of enrollment of children identified with special needs and disability across the study countries, with some countries achieving a higher level of participation than others.

\section{Children from a Minority Ethnic Group}

The enrollment data on children from a minority ethnic group reveal that the proportion of children falling into this group varies significantly in the three study countries that submitted data, $1 \%$ in Denmark, $11 \%$ in Estonia and $49-51 \%$ in the United States. In Denmark and Estonia, the enrollment level of these children is very high: in Denmark, 97\% for PPE and, in Estonia, 100\% for both. In the United States, where there is targeted funded entitlement, the enrollment level is significantly lower, $21 \%$ for ECED, 28\% for PPE up to the age of kindergarten, and 34\% for kindergarten.

\section{Children whose Home Language is Different than the National Language}

For the two countries that submitted enrollment data on children whose home language differs from the national or dominant language, the proportion of children falling into this group is 17\% in Estonia and 9-12\% in the United States. In Estonia, where there is publicly-funded universal ECE, the enrollment level of these children is very high: $100 \%$ for ECED and PPE.

\section{Summary Finding 15}

There is significant variation between the study countries as to the number of children in the population who are from low-income families, have special needs or disability, are from minority ethnic groups, and whose home language is different from the national language. In some countries, these subgroups can form a very sizable element of the population and, in others, a much smaller element, and this has implications for policy choices. Even given this variation, data from the four study countries that submitted evidence reveal differences in the level of enrollment of children from these subgroups, with the two reporting countries offering publiclyfunded universal ECE having a significantly higher level of participation of these subgroups than the two countries where there is targeted funded entitlement. 


\section{Prioritizing or Targeting Strategies for ECE Enrollment}

Recent evidence has shown (EIU, 2012; OECD, 2012b; Pascal \& Bertram, 2012) that many countries have a policy strategy of prioritizing or targeting their ECE programs towards children who are considered to be at risk of school failure, such as low-income families, children with special needs or disability, or children whose home language is other than the national language.

Prioritizing regulations in the study countries may give preferential enrollment to certain subgroups of children, including a focus on parental unemployment and low income, residential criteria (living in a specified local catchment area near the setting), special needs or disability, minority ethnic groups, language spoken at home not being the national language, and elder siblings being already enrolled in the school (Table 13).

Table 13: Existence and focus of prioritizing regulations for children aged 0-3 years (ECED) and children aged from 3 to the start of primary schooling (PPE)

\begin{tabular}{|c|c|c|c|c|c|c|c|c|}
\hline \multirow[b]{2}{*}{ Country ${ }^{a}$} & \multirow[b]{2}{*}{ Level } & \multicolumn{7}{|c|}{ Focus of centrally prescribed prioritizing regulations for ECE places } \\
\hline & & 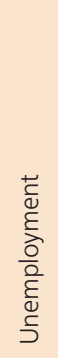 & 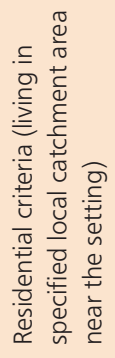 & 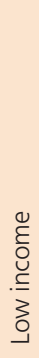 & 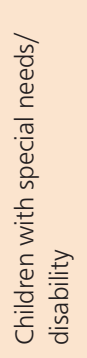 & 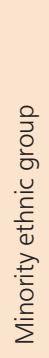 & 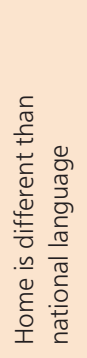 & 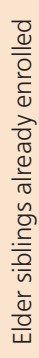 \\
\hline \multirow[t]{2}{*}{ Chile } & ECED & - & O & ○ & O & O & O & O \\
\hline & PPE & - & O & $\bullet$ & $\bullet$ & O & O & O \\
\hline \multirow[t]{2}{*}{ Czech Republic } & ECED & - & - & - & - & - & - & - \\
\hline & PPE & O & - & $\bullet$ & O & O & O & • \\
\hline \multirow[t]{2}{*}{ Poland b } & ECED & - & - & - & - & - & - & - \\
\hline & PPE & O & O & O & O & O & O & O \\
\hline \multirow{2}{*}{$\begin{array}{l}\text { Russian } \\
\text { Federation }\end{array}$} & ECED & O & O & O & $\bullet$ & O & 0 & O \\
\hline & PPE & O & O & O & • & O & O & O \\
\hline \multirow[t]{2}{*}{ United States } & ECED & O & O & $\bullet$ & $\bullet$ & $\bullet$ & O & O \\
\hline & PPE & O & • & - & $\bullet$ & & O & - \\
\hline
\end{tabular}

Key:

- Yes, centrally prescribed regulations with specific focus exist.

O No, centrally prescribed regulations with specific focus do not exist. No prioritizing regulations.

\section{Country specific notes:}

a In Denmark, Estonia and Italy, universal entitlement and access is in place (in Italy for PPE only) and so the NRCs reported no need for prioritizing regulations. In Italy the situation is mixed for ECED, since there are criteria for priority access to places in ECED but they are generally defined at the local level, in coherence with national purposes of ECED. Criteria usually include a combination of the following elements: parental occupation status; working mothers; low income; children with certified disability or special needs; children in social services; children with one parent only; children whose parents are both employed; families with multiple children; twins; and foreign children. Proximity to the setting could also be among these criteria. Similar criteria are set at the local level also for assigning free PPE places.

b In Poland, there are prioritizing regulations for children from three to start of primary school, but the law is currently under implementation so priority groups are not yet identified. 
Five of the eight study countries have national regulations for prioritizing enrollment in ECE services for certain population subgroups, with Chile, the Russian Federation and the United States using them for ECED, and Chile, the Czech Republic, Poland, the Russian Federation and the United States using them for PPE (Table 13). In other countries (Denmark, Estonia and Italy's PPE), it was reported that all children have universal access and so prioritizing policies are not required. The most common focus among the study countries for the prioritizing regulations are children whose parents have low income (used in Chile, the Czech Republic and the United States) and children with special needs or disability (used in Chile, the Russian Federation and the United States).

For example, in Chile, the national program, "Chile Grows With You" is the main program that allocates priority for ECED places to children from low-income families. This program guarantees a range of support services for children in vulnerable conditions, including free access to ECE. However, in order to have access to these services, the mother, father or guardian of the child must be working, searching for work, or studying. In Poland, new legislation has been passed which, when implemented, will prioritize children with disabilities, children with parents with disabilities, children from large families, children from foster families, and children raised by a single parent. In the Russian Federation, there are national regulations at both ECED and PPE level that give priority admission to children of large families, children with disabilities, children with disabled parents, children of single mothers, and children of soldiers, police officers, internal affairs officers and other Federation officers. In addition, there are regulations that give children "extraordinary" admission to ECE, such as children whose parents were exposed to radiation as result of the Chernobyl disaster, children who are deemed at risk, children of judges and prosecutors, and children with parents in the investigating authority of the Russian Federation. Regions can also establish additional admission priorities, such as minority ethnic group and residential criteria. In the United States, Head Start and Early Head Start target children from low-income families and reserve places for children with special needs or disabilities.

It should be noted that those study countries that do not have national prioritizing regulations may have local criteria to prioritize the allocation of ECE places. For example, in Italy, although there are general guidelines but no national prioritizing regulations, at a local level there are criteria that determine the priority of enrollment to ECE services for certain children. At the ECED level these criteria include parental occupation status or low income, children with certified disability, children being supported by social services, children of single parents, children where both parents are employed, children of ethnic minority groups, and children of families with multiple children. For children over the age of three years, PPE is universal, but again there are locally employed criteria to form waiting lists for available PPE places, giving preferential access to children with disabilities, difficult home circumstances or multiple disadvantages. In Poland, for children at ECED level, communes are responsible for setting the rules for allocating places to families and there are no central regulations. In Denmark and Estonia, it is reported that there is no need for prioritizing regulations, because all children are guaranteed a place in child care from the age of one year. 


\section{Summary Finding 16}

Prioritizing regulations or targeting strategies to allocate ECE places preferentially are commonly used in the study countries at national and/or local level. The study countries use a range of social, developmental and economic criteria to focus the targeting strategies, with the most common prioritizing regulations aimed at enhancing the participation in ECE of children from low-income families, and children with special educational needs or disability.

\section{Diversity and Cultural Responsiveness of Settings}

The capacity of ECE services to deal with diversity in the child population has been shown to be a clear factor in the delivery of quality ECE services, increased participation of children in the services and the achievement of positive educational outcomes (Reid, \& Kagan, 2015; Reid, \& Ready, 2013; Sylva et al., 2008). The evidence from these studies show that developing ECE provision for diversity leads to enhanced child participation and better outcomes for the less advantaged.

The ECES policy data identified a possible range of policy strategies used in the study countries to ensure ECE settings support and facilitate diversity and cultural responsiveness (Table 14). These strategies included: legislation to ensure cultural diversity is respected in ECE programs; prioritized access to ECE for certain cultural groups; controlled eligibility requirements for ECE programs; promotion of cultural diversity in ECE programs, including linguistic diversity; training of staff to ensure cultural diversity is respected in ECE programs; additional specialist staff to support cultural diversity; targeted recruitment of staff to ensure cultural diversity is reflected in settings; additional budget to support cultural diversity; and additional equipment to support cultural diversity.

All the study countries have strategies to facilitate cultural diversity in ECE programs, except at the ECED level in the Czech Republic and Poland (Table 14). In all the study countries this includes legislation to ensure cultural diversity is respected in ECE programs. In Chile, for example, the first paragraph of the General Law on Education (Law 20.370) states that the education system should promote and ensure the diversity of educational processes and programs, as well as the cultural, religious and social diversity of their students. It also states that the educational system should recognize the ethnic background of all the students. In Denmark, law prescribes cultural diversity in all ECE centers. In Italy, Law 295/1997 specifically provides funds for projects that aim to support foreign minors and provide affirmative actions for the respect of diversity, including the cultural diversity of ethnic minorities. Based on this law, ECED centers have been created with specific attention to cultural diversity. At PPE level, Chilean JUNJI has an alternative program, called the Intercultural Preschool, which supports children from two to five years of age from the native communities. In the Russian Federation, the legal standards for preschool education require settings to take into account the ethno-cultural background of the child and ensure equal opportunities for each child regardless of residence, gender, nationality, language, social status and other features. Diversity is also supported through the requirements of the educational program. 
Table 14: Diversity and cultural responsiveness strategies for children aged 0-3 years (ECED) and children aged from 3 years to the start of primary schooling (PPE)

\begin{tabular}{|c|c|c|c|c|c|c|c|c|c|c|}
\hline \multirow[b]{2}{*}{ Country } & \multirow[b]{2}{*}{ Level } & \multicolumn{9}{|c|}{ Strategies to facilitate cultural diversity } \\
\hline & & 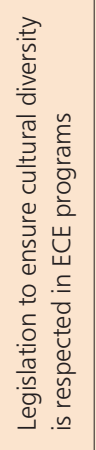 & 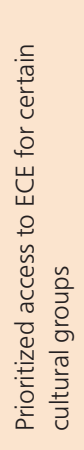 & 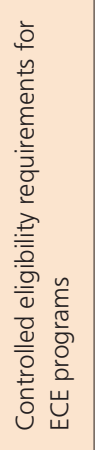 & 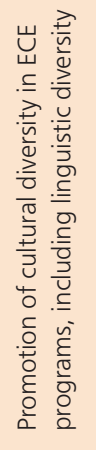 & 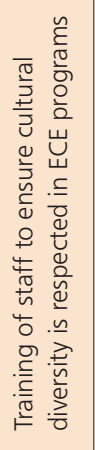 & 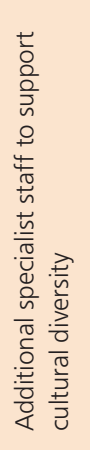 & 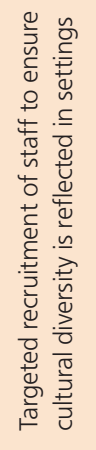 & 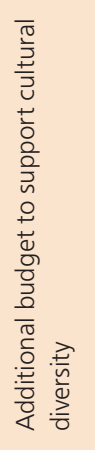 & 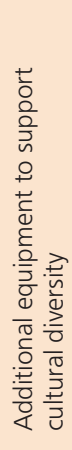 \\
\hline \multirow[t]{2}{*}{ Chile } & ECED & $\bullet$ & O & O & O & O & O & O & O & O \\
\hline & PPE & $\bullet$ & O & O & $\bullet$ & O & O & O & O & O \\
\hline \multirow[t]{2}{*}{ Czech Republic } & ECED & - & - & - & - & - & - & - & - & - \\
\hline & PPE & $\bullet$ & O & O & $\bullet$ & $\bullet$ & $\bullet$ & O & O & O \\
\hline \multirow[t]{2}{*}{ Denmark } & ECED & $\bullet$ & O & $\bullet$ & $\bullet$ & O & O & O & 0 & O \\
\hline & PPE & $\bullet$ & 0 & $\bullet$ & $\bullet$ & O & 0 & 0 & O & 0 \\
\hline \multirow[t]{2}{*}{ Estonia } & ECED & $\bullet$ & $\bullet$ & $\bullet$ & $\bullet$ & $\bullet$ & $\bullet$ & - & • & $\bullet$ \\
\hline & PPE & $\bullet$ & $\bullet$ & $\bullet$ & $\bullet$ & $\bullet$ & $\bullet$ & $\bullet$ & $\bullet$ & $\bullet$ \\
\hline \multirow[t]{2}{*}{ Italy } & ECED & $\bullet$ & 0 & 0 & - & 0 & 0 & 0 & 0 & 0 \\
\hline & PPE & $\bullet$ & O & O & $\bullet$ & $\bullet$ & O & O & $\bullet$ & 0 \\
\hline \multirow[t]{2}{*}{ Poland } & ECED & - & - & - & - & - & - & - & - & - \\
\hline & PPE & $\bullet$ & 0 & 0 & O & 0 & 0 & 0 & 0 & 0 \\
\hline \multirow{2}{*}{$\begin{array}{l}\text { Russian } \\
\text { Federation }\end{array}$} & ECED & - & O & O & $\bullet$ & 0 & O & O & O & O \\
\hline & PPE & $\bullet$ & 0 & 0 & $\bullet$ & 0 & 0 & O & O & O \\
\hline \multirow[t]{2}{*}{ United States } & ECED & $\bullet$ & $\bullet$ & $\bullet$ & $\bullet$ & $\bullet$ & $\bullet$ & $\bullet$ & $\bullet$ & $\bullet$ \\
\hline & PPE & $\bullet$ & $\bullet$ & $\bullet$ & $\bullet$ & $\bullet$ & $\bullet$ & $\bullet$ & $\bullet$ & $\bullet$ \\
\hline $\begin{array}{ll}\text { Key: } \\
-\quad \text { Yes, strateg } \\
0 \quad \text { No, strateg } \\
-\quad \text { Strategies }\end{array}$ & a a sp & †OC & 8 & t. & a level & & & & & \\
\hline
\end{tabular}

A range of other strategies are also used to achieve cultural responsiveness in practice in the study countries. The most commonly used strategy is the active and positive promotion of cultural diversity, including linguistic diversity, which is evident in Denmark, Estonia, the Russian Federation and the United States for both ECED and PPE services, and in Chile and the Czech Republic for PPE services. Italy employs a range of strategies, with a recent particular emphasis on the integration of migrant children into the educational system. There is also a limit of $30 \%$ of foreign children per classroom to ensure proper care is given to such children, starting from PPE. 


\section{Summary Finding 17}

The promotion of culturally and linguistically responsive practices in ECE settings to increase the enrollment and participation of children from diverse social and cultural backgrounds is evident in all the study countries, and backed up by legislation.

\section{Coverage and Availability of ECE Provision}

There have been several international reports that have encouraged a universal approach to ECE access, with particular attention to improving coverage and availability of ECE for children below the age of three years and to children from low-income homes and with special needs or disability (Corak et al., 2012; EIU, 2012; OECD, 2012b, 2013; Pascal, \& Bertram, 2012). The potential benefits to children's developmental outcomes are a key part of the rationale for improving participation in ECE services. These reports also state that more attention needs to be devoted to:

- Providing universal and responsive services for all three- to six-year-olds to ensure provision meets the needs of a particular child or his or her parent(s). For example, a child may have special learning needs and require an inclusive program in the local center, or working parents may need flexible and year-round opening hours.

- Expanding provision for infants and toddlers to ensure it is affordable and available for all children.

- Ensuring equitable access to ECE, such that all children have equal opportunities to attend quality ECE, regardless of family income, parental employment status, special educational needs, or ethnic/language background.

- Ensuring there is coverage of provision in all geographic areas, particularly rural and remote areas where sustainability of ECE services can be more difficult due to a dispersed and less dense population.

Admissions policies define how all children will be considered for entry into a setting and any order of priority that will be applied if there are insufficient places to meet demand. Settings may serve a particular age group, religion/community, or have other entry criteria which determine the profile of the families that they serve. Children may only be accepted if they have reached a certain developmental stage (such as being able to use the toilet independently) and this may affect the acceptance of children with physical disabilities or developmental delay. For settings which are not free at the point of provision, parents' ability to pay will affect which settings their children are able to attend.

Universal coverage (as opposed to universal entitlement) of ECE services at ECED and PPE levels varies among the study countries (Table 15). In some countries universal coverage does not exist, and NRCs provided information on areas of limited service availability, in particular service coverage for children living in rural areas, children from low-income families and children with special needs or disability.

Denmark, Estonia and the Russian Federation have universal coverage of services for children under the age of three (ECED), and Chile, the Czech Republic, Italy, Poland and the United States do not (Table 15). For children from three years to primary school age (PPE), six of the eight study countries have universal coverage of services, including 
Table 15: Existence of universal coverage of services for children aged 0-3 years (ECED) and children aged 3 to the start of primary school (PPE) and areas of limited service availability

\begin{tabular}{|c|c|c|c|c|c|}
\hline \multirow[b]{2}{*}{ Country } & \multirow[b]{2}{*}{ Level } & \multirow[b]{2}{*}{$\begin{array}{l}\text { Existence of ECE } \\
\text { universal coverage }\end{array}$} & \multicolumn{3}{|c|}{ Areas of limited availability of ECE services } \\
\hline & & & Rural areas & $\begin{array}{l}\text { Low-income } \\
\text { families }\end{array}$ & $\begin{array}{l}\text { Children with } \\
\text { special needs or } \\
\text { disability }\end{array}$ \\
\hline \multirow[t]{2}{*}{ Chile } & ECED & $\diamond$ & $\bullet$ & O & - \\
\hline & PPE & $\diamond$ & - a & O & O \\
\hline \multirow[t]{2}{*}{ Czech Republic } & ECED & $\diamond$ & - & - & - \\
\hline & PPE & $\diamond$ & 0 & 0 & O \\
\hline \multirow[t]{2}{*}{ Denmark } & ECED & $\diamond$ & 0 & O & O \\
\hline & PPE & $\diamond$ & 0 & O & O \\
\hline \multirow[t]{2}{*}{ Estonia } & ECED & $\diamond$ & 0 & 0 & O \\
\hline & PPE & $\diamond$ & O & O & ○ \\
\hline \multirow[t]{2}{*}{ Italy } & ECED & $\diamond b$ & - & - & - \\
\hline & PPE & $\diamond c$ & - & - & - \\
\hline \multirow[t]{2}{*}{ Poland } & ECED & $\diamond$ & $\bullet$ & - & - \\
\hline & $\mathrm{PPE}^{a}$ & $\bullet$ & - d & - & - \\
\hline \multirow{2}{*}{$\begin{array}{l}\text { Russian } \\
\text { Federation }\end{array}$} & ECED & $\diamond$ & O & O & O \\
\hline & PPE & $>$ e & O & O & O \\
\hline \multirow[t]{2}{*}{ United States } & ECED & $\diamond$ & 0 & $\bullet$ & - \\
\hline & PPE & $\nabla_{f}$ & 0 & $\bullet$ & - \\
\hline
\end{tabular}

Key:

Existence of universal coverage:

- Yes.

$\diamond$ No.

Limited availability

- Yes.

O No.

- No data available.

Country specific notes:

a Chile: There is universal coverage in PPE only for children from four years therefore there is limited availability for children in rural areas between three to four years.

b Italy: ECED is not available for all children. Poorer coverage and availability in ECED are not limited to certain groups only, but for the entire 0-3 population, since there are very few centers opened compared to the potential demand. This is especially true in the south of Italy, where PPE centers are partially subsidizing ECED with the free provision of Sezioni Primavera for children 24-36 months old and with anticipated enrollments. ECE coverage could also be limited in big cities, but there are no national data to back this statement.

c Italy: PPE is promoted as a universal public service, free of charge for families, but it does not have universal coverage as it is not mandatory; coverage is high, but has been declining in recent years. The lack of data prevents a detailed analysis of the population segments mostly affected by this decline.

d Poland: Although there is universal coverage in theory, in practice this does not secure a place in PPE until a child is five years old (and from September 2015 this applies for four-year-olds) when they have to attend compulsory one year of preschool. In all other cases, parents apply for a place in PPE, but in certain rural areas of Poland there is a shortage of places for three- and four-year-olds.

e Russia: Although there is universal coverage, there are certain areas that have a shortage of PPE places as a result of the 2006-2013 "baby boom."

f United States: Kindergarten (the final year of ISCED Level 0) could be considered universal, however the earlier years of PPE have limited availability. 
Chile, the Czech Republic, Denmark, Estonia, Poland and the Russian Federation; Italy and the United States have not achieved universal coverage. More countries report universal coverage as children move into PPE. Italy and the United States both report that, even though there is no universal coverage, during the final year of PPE coverage could be considered universal, as there is almost universal access. Even where universal entitlement to services exists, some study countries report a shortage of provision, particularly in rural areas (Chile, Estonia and Poland), for low-income families (Estonia and the United States), and for children with special needs or disability (Estonia and the United States).

\section{Summary Finding 18}

There is more universal coverage of ECE services at PPE level than at ECED level. Shortage in ECE places is greater for children under the age of three years, and these shortages can be more acute for children living in rural areas, from a low-income family, or who have special needs or disability.

Where universal coverage is not available and barriers to participation in ECE exist for certain groups, some countries have adopted national strategies to increase service coverage and encourage participation (EIU, 2012; Pascal, \& Bertram, 2012). Such strategies might include: increasing geographical coverage in urban or rural areas and low-income neighborhoods; encouraging the extension of all year round services, including holiday periods; extending the hours of opening to include early morning and later evening opening; and introducing full week opening, including weekends. The eight study countries have various strategies to increase coverage of ECE services (Table 16).

Seven of the study countries have adopted national strategies to increase the coverage of ECE services (Table 16). Chile, Denmark, Estonia, Italy and the Russian Federation have national strategies that include both ECED and PPE level services; in the Czech Republic, such strategies were aimed at PPE level services only, and, in Poland, they were aimed at ECED level services only. Among the study countries, the most common strategy aims to increase geographical coverage of the provision, in rural or urban areas, or in low-income neighborhoods (Chile and Denmark). Chile and Estonia have also increased opening hours and encouraged all year round availability of services.

The Czech Republic stated that they have a long-term strategy to increase capacity in schools in areas where provision levels are low, and to extend the age covered by PPE so that two-year-olds are officially included. Italy reported that there is an effort to increase coverage of ECE services, especially for children under the age of three years (ECED), by offering funding to increase the number of new places where coverage is low. Poland is also providing capital grants to create more ECE services in certain geographical areas. In the Russian Federation, there has been an increase in the number of children allowed within child:staff ratios to extend the coverage of services. 
Table 16: Strategies to increase coverage of ECE provision for children aged 0-3 years (ECED) and children aged 3 to the start of primary school (PPE)

\begin{tabular}{|c|c|c|c|c|c|c|c|}
\hline \multirow[b]{2}{*}{ Country } & \multirow[b]{2}{*}{ Level } & \multirow[b]{2}{*}{ 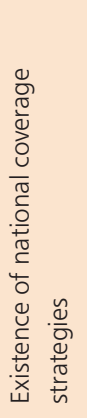 } & \multicolumn{5}{|c|}{ Strategies to increase coverage of ECE } \\
\hline & & & 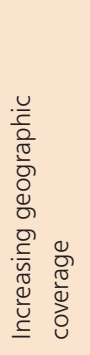 & 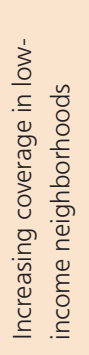 & 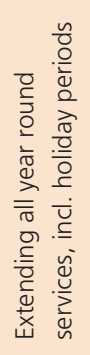 & 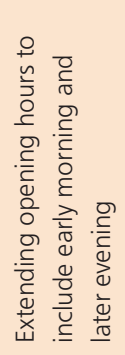 & 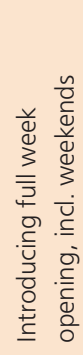 \\
\hline \multirow[t]{2}{*}{ Chile } & ECED & $\diamond$ & $\bullet$ & $\bullet$ & $\bullet$ & $\bullet$ & O \\
\hline & PPE & $\diamond$ & $\bullet$ & $\bullet$ & $\bullet$ & $\bullet$ & O \\
\hline \multirow[t]{2}{*}{ Czech Republic } & ECED & $\diamond$ & $\mathrm{n} / \mathrm{a}$ & $n / a$ & $n / a$ & $\mathrm{n} / \mathrm{a}$ & $\mathrm{n} / \mathrm{a}$ \\
\hline & PPE & $\bullet$ & O & O & O & O & O \\
\hline \multirow[t]{2}{*}{ Denmark } & ECED & $\diamond$ & $\bullet$ & $\bullet$ & $\bullet$ & O & O \\
\hline & PPE & $\bullet$ & $\bullet$ & $\bullet$ & $\bullet$ & O & O \\
\hline \multirow[t]{2}{*}{ Estonia } & ECED & $\bullet$ & $\bullet$ & O & $\bullet$ & $\bullet$ & 0 \\
\hline & PPE & $\diamond$ & $\bullet$ & 0 & $\bullet$ & $\bullet$ & 0 \\
\hline \multirow[t]{2}{*}{ Italy } & ECED & $\bullet$ & $\bullet$ & O & O & O & O \\
\hline & PPE & $\diamond$ & $\bullet$ & 0 & 0 & 0 & 0 \\
\hline \multirow[t]{2}{*}{ Poland } & ECED & $\diamond$ & $\bullet$ & O & O & O & O \\
\hline & PPE & $\diamond$ & $n / a$ & $n / a$ & $n / a$ & $n / a$ & $n / a$ \\
\hline \multirow{2}{*}{$\begin{array}{l}\text { Russian } \\
\text { Federation }\end{array}$} & ECED & $\bullet$ & $\bullet$ & O & 0 & 0 & O \\
\hline & PPE & $\bullet$ & $\bullet$ & 0 & 0 & 0 & 0 \\
\hline \multirow[t]{2}{*}{ United States } & ECED & $\diamond$ & $\mathrm{n} / \mathrm{a}$ & $\mathrm{n} / \mathrm{a}$ & $n / a$ & $\mathrm{n} / \mathrm{a}$ & $n / a$ \\
\hline & PPE & $\diamond$ & $n / a$ & $\mathrm{n} / \mathrm{a}$ & $\mathrm{n} / \mathrm{a}$ & $\mathrm{n} / \mathrm{a}$ & $n / a$ \\
\hline
\end{tabular}

Key:

Existence of national or typical subnational ECE coverage strategies:

$\diamond$ Yes.

$\diamond$ No.

Types of strategies:

- Yes.

O No.

- Not applicable.

\section{Summary Finding 19}

In the seven study countries where there is a national commitment to achieve universal coverage of ECE services, strategies have been adopted to increase the geographic coverage of services and to extend their opening hours, in order to enhance the participation of all children. 


\section{Costs to Parents for Participation in ECE}

In most countries, costs for ECE are shared between parents and governments. In only a few countries is the public provision of high-quality ECE for children considered an entitlement for a child, on an equal footing with services for the older children, and funded as such. Even where there is universal ECE provision, parental fees are often charged up to the year before entry into compulsory schooling, but costs to parents are generally low; sometimes fees are based on parental income and sometimes they are capped at a limit, with low-income groups paying only token fees. OECD (2013) data showed that in the continental European countries, public ECE programs largely predominated, and parents contributed on average $25-30 \%$ to their costs. Countries such as Belgium, France and the Netherlands provide universal and free early education services to children from a young age. In other countries, the parental share of funding is significantly higher, and can be up to $82 \%$ of costs in some Canadian provinces and full costs in many American services. Australia is unusual in that fee support (the Child Care Benefit and a new $30 \%$ child care tax rebate) is available to $98 \%$ of parents, with low-income parents receiving a higher benefit. This means that approximately $60 \%$ of expenditure on all early childhood services is public, with parents contributing in total about $38 \%$ of costs. The general picture then is that, in Europe, governments contribute about $66-90 \%$ of costs, and parents pay less than one-third. In many other countries, the situation is reversed, with parents paying the major share and governments providing about one-third of costs (Australia about 60\%). The evidence is that this high cost to parents has become a real disincentive to women remaining in the labor force, particularly if a second child is born; it also impacts directly on some children accessing high-quality ECE services, which can enhance their developmental outcomes (Corak et al., 2012; EIU, 2012; Pascal, \& Bertram, 2012).

Differences in ECE fee structures will partly depend on governmental funding of ECE. The fee structure varies across countries and is dependent on national policy decisions about the balance of public and private funding, as well as on the types of ECE provision available (OECD, 2012a). Even within Europe, where there is more publicly-funded provision, the level of subsidy varies: for example, one study found that the share that parents paid ranged from 8\% in Sweden to 80\% in Poland (Janta, 2009).

The ECES explored the proportion of ECE costs borne by parents for accessing ECE services in the eight participating countries. The study countries reported that accessing data about costs of ECE borne by parents is very difficult and, in many cases, data could not be reported, only estimated figures could be provided, or just an overall statement about the balance of the costs borne by parents could be supplied.

The data provided suggest that, in the study countries, the costs to parents for their child's ECE participation varies considerably from no cost to around $25 \%$ of costs. For example, in Chile, for children under four years old, public provision is free and so there is no cost to parents. Private subsidized services for children from four years to primary school may charge fees (which might be subsidized) to parents, and, in fully private provision, parents bear all the costs. In Denmark, parents pay $25 \%$ of the fees for services from birth to six years (ECE). In Estonia, the Preschool Childcare Institution Act states that the amount covered by parents per child must not exceed $20 \%$ of the minimum wage rate established by the government. In Italy, it is estimated that the costs borne by parents are approximately 19.2\% of total ECED costs (Istat, 
2014; data referring to 2012). In the United States, the cost of ECE borne by parents ranges from $8 \%$ for children less than one year of age to $5 \%$ for children from five to six years of age, generally decreasing with the age of the child.

\section{Summary Finding 20}

The findings from the study countries indicate that ascertaining the costs of ECE services to parents can be difficult, as charging policy and practice are generally not nationally documented. However, where free, universal, publicly-funded ECE services are unavailable, there is evidence that these costs can constitute a significant proportion of household income. It also implies that the costs to parents may be a significant factor when looking at levels of child enrollment in ECE services.

\section{Targeted Early Intervention Programs}

Cost-benefit analysis of investment in high-quality early education programs (Heckman, 2012) demonstrates that the highest per child benefits stem from programs that target economically disadvantaged children. Indeed, studies have shown that these children make significant gains in cognition, social-emotional development, and educational performance when they participate in high-quality early education programs, relative to children who do not participate (Corak et al., 2012; Pascal, \& Bertram, 2012; Sylva et al., 2008). Lynch (2007) identified the benefits from investment targeted to lower-income families. This research indicated that targeted investments, while less ambitious (costing roughly $25 \%$ of the costs of universal investment), would yield higher benefits, as children from middle- and high-income households are likely to already receive higher quality educational development in their prekindergarten years. Research suggests that there are certain subgroups in the population targeted for early intervention (Corak et al., 2012; EIU, 2012; Pascal, \& Bertram, 2012). These subgroups include low-income families, children with special needs or disability, minority ethnic groups, and children for whom the home language spoken is other than the national language (Table 17).

All of the study countries, except Italy, have targeted intervention programs (Table 17), which suggests that they are well aware of the benefits of these targeted programs. These programs are also evident in the many of the countries that offer universal publicly-funded ECE services. In Italy universal access and inclusion are provided as an alternative to programs targeting specific groups in the population. However, although there are no strategies for additional support to specific groups in Italy, it is reported that low-income families may apply for vouchers or subsidies based on family income level. Within ECE services, there are also teachers who are specialized in teaching disabled children.

In the majority of study countries, the intervention programs are implemented in both the ECED and PPE age phases, but, in the Czech Republic, they are implemented at PPE level only. All the identified subgroups are targeted in the study countries that have intervention programs, with the exception of Chile which, during the ECED phase, does not target children with special needs or disability or children whose home language differs from the official national language. Low-income families and minority ethnic groups are targeted for early intervention in all the study countries that have a national intervention strategy. 
Table 17: Existence of targeted early intervention programs at target groups for children aged 0-3 years (ECED) and children aged 3 to the start of primary schooling (PPE)

\begin{tabular}{|c|c|c|c|c|c|}
\hline \multirow[b]{2}{*}{ Country } & \multirow[b]{2}{*}{ Level } & \multicolumn{4}{|c|}{ Target groups for early intervention programs } \\
\hline & & $\begin{array}{l}\text { Low-income } \\
\text { families }\end{array}$ & $\begin{array}{l}\text { Children with } \\
\text { special needs } \\
\text { disability }\end{array}$ & $\begin{array}{l}\text { Minority } \\
\text { ethnic } \\
\text { groups }\end{array}$ & $\begin{array}{c}\text { Language spoken at } \\
\text { home is different to } \\
\text { national language }\end{array}$ \\
\hline \multirow[t]{2}{*}{ Chile } & ECED & $\bullet$ & - & $\bullet$ & - \\
\hline & PPE & $\bullet$ & $\bullet$ & • & - \\
\hline \multirow[t]{2}{*}{ Czech Republic } & ECED & - & - & - & - \\
\hline & PPE & $\bullet$ & $\bullet$ & $\bullet$ & $\bullet$ \\
\hline \multirow[t]{2}{*}{ Denmark } & ECED & $\bullet$ & $\bullet$ & $\bullet$ & $\bullet$ \\
\hline & PPE & $\bullet$ & $\bullet$ & $\bullet$ & $\bullet$ \\
\hline \multirow[t]{2}{*}{ Estonia } & ECED & $\bullet$ & $\bullet$ & $\bullet$ & $\bullet$ \\
\hline & PPE & $\bullet$ & $\bullet$ & $\bullet$ & $\bullet$ \\
\hline \multirow[t]{2}{*}{ Italy } & ECED & - & - & - & - \\
\hline & PPE & - & - & - & - \\
\hline \multirow[t]{2}{*}{ Poland } & ECED & $\bullet$ & $\bullet$ & $\bullet$ & $\bullet$ \\
\hline & PPE & $\bullet$ & $\bullet$ & $\bullet$ & $\bullet$ \\
\hline \multirow{2}{*}{$\begin{array}{l}\text { Russian } \\
\text { Federation }\end{array}$} & ECED & $\bullet$ & $\bullet$ & $\bullet$ & $\bullet$ \\
\hline & PPE & - & $\bullet$ & $\bullet$ & $\bullet$ \\
\hline \multirow[t]{2}{*}{ United States } & ECED & $\bullet$ & $\bullet$ & $\bullet$ & - \\
\hline & PPE & - & $\bullet$ & • & - \\
\hline
\end{tabular}

Key:

- Existence of targeted intervention programs at national or typical subnational level.

- $\quad$ Targeted intervention programs do not exist at national or typical subnational level.

In Estonia, there is a particular focus on early intervention for children whose home language differs from the national language. It is reported that, in 50\% of ECE settings, specialist professional staff are provided to support the targeted groups with speech and language therapists and "special" pedagogues. If progress cannot be made with the child's language development, the preschools and parents can access additional advice from regional centers offering a wider range of specialist support. In those settings where the education is not conducted in Estonian, there is specialist support offered for Estonian language training. In cooperation with the National Examinations and Qualifications Center and Lasteveeb Open University, internet-based study material has also been developed to support the learning of Estonian as a second language for preschool children. The Russian Federation provides targeted support programs at a regional level, which offer support for minority ethnic groups. The United States provides resources to support culturally and linguistically diverse communities. There are also programs such as Head Start that target certain populations, such as Native Americans and Alaska Native children and families. 


\section{Summary Finding 21}

Targeted intervention programs as part of ECE services are used extensively in the majority of study countries as a mechanism to provide additional and early support for children from low-income families, children from minority ethnic groups, children with special needs or disability, and children whose home language differs from the national language. The intervention may take a variety of forms, including input from specialist professionals, providing additional resources, running support groups, providing specialist advice, and accessing internet-based study material.

Open Access This chapter is distributed under the terms of the Creative Commons AttributionNonCommercial 4.0 International License (http://creativecommons.org/licenses/by-nc/4.0/), which permits any noncommercial use, duplication, adaptation, distribution and reproduction in any medium or format, as long as you give appropriate credit to the original author(s) and the source, provide a link to the Creative Commons license and indicate if changes were made.

The images or other third party material in this chapter are included in the works Creative Commons license, unless indicated otherwise in the credit line; if such material is not included in the works Creative Commons license and the respective action is not permitted by statutory regulation, users will need to obtain permission from the license holder to duplicate, adapt or reproduce the material. 